\title{
A PERFORMANCE MEASUREMENT SYSTEM FOR VIRTUAL AND EXTENDED ENTERPRISES
}

\author{
Juan José Alfaro Saiz, Raúl Rodríguez Rodríguez, Angel Ortiz Bas \\ Department of Business Organisation, Financial Economy and Accounting, Polytechnic \\ University of Valencia, SPAIN; \\ jalfaro@omp.upv.es, raurodro@upvnet.upv.es, aortiz@omp.upv.es
}

\begin{abstract}
Nowadays, enterprises seek to improve their operations and results by collaborating within networks of enterprises. Then, it is necessary to have available a method for monitoring and controlling how both Virtual Enterprises (VE) and Extended Enterprises (EE) are performing. For doing so, an efficient and effective performance measurement system (PMS) should be applied. An extensive literature review was conducted to find out existing feasible PMSs that really covered this field properly. As a result, it was found out that there was not a framework that fully accomplished these tasks, being then developed the one called Performance Measurement System for Extended and Virtual Enterprises (PMS-EVE). The PMS-EVE framework is built on the concepts of trust and equity to be present within the relationships among the different components of the $V E / E E$.
\end{abstract}

\section{INTRODUCTION}

In the last years, market globalisation has been favoured for the advances experimented by Information and Communication Technologies (ICT), mainly with the apparition and huge spreading of the Internet. This fact has increased competitiveness among organisations, demanding a quick adaptation to face market requirements. Consequently, organisations seek to establish collaborations with others ones, aiming to strength their weaknesses by facing common objectives. Such organisations that cooperate and collaborate among them through their human capital and supported by ICT are known as Collaborative Networked Organisations (CNO) (Dyer, 2000).

Such collaboration maximise the combined capacities allowing each enterprise to reach its strategic objectives by providing integrated solutions to its customers' needs. 
According to (Riis, 1997) these CNOs can be mainly classified into Extended Enterprises (EE) and Virtual Enterprises (VE). Additionally, (Moller et al. , 1997) identifies the EE with a Supply Chain and the VE with a Virtual Organisation.

EE span company boundaries and include complex relationships between a company, its partners, customers, suppliers and market (Browne, Sackett and Wortmann, 1994), (Caskey, 1995). As "Figure 1" shows, EE can be defined as an entity where the dominant company extents its vision and relies fully on others members for key aspects of the value chain such as distribution, logistics and direct sales to final customers. Companies in an extended enterprise must co-ordinate their internal systems (intra-organisational activities) with other systems within the supply chain, being flexible enough to adapt to changes.

On the other hand, (Preiss, 1996) defines a Virtual Organisation as a collection of business units where people and work processes from these business units interact intensively for carrying out work that mutually benefits all the parts. More specifically, numerous authors have defined VE, An obtained definition in "The Economist" (February, 1993) affirms that a VE is a temporal network of organisations that get joined to exploit a specific market opportunity supported by the technological capabilities of the companies that compose the network; (Riis, 1997) states that a VE is characterised by complementary contributions coming from different companies where one of these plays the broker role and without leader, relying their survival on the attitude of all the companies. "Figure 1" illustrates the mentioned concepts.

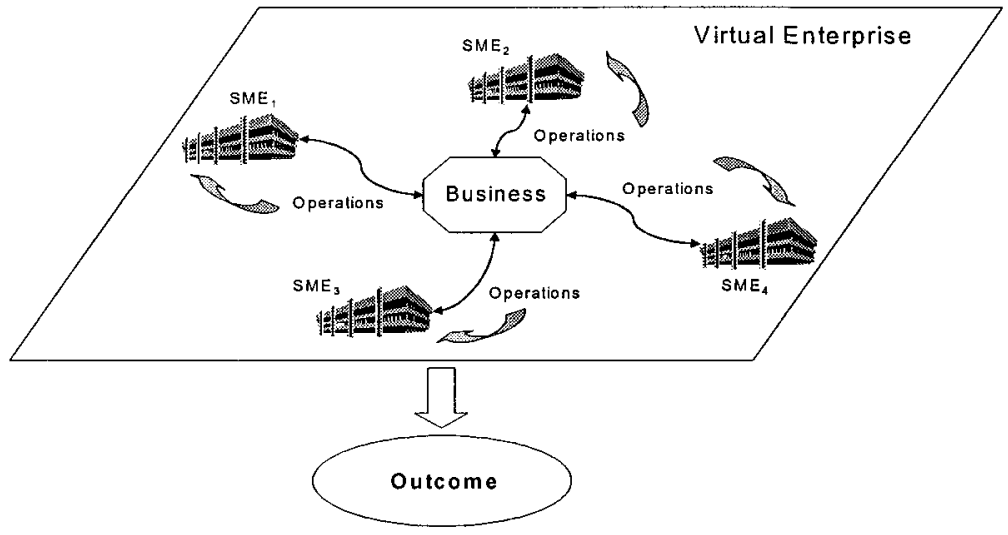

Figure 1: Virtual Enterprise

Due to the extensive degree of proliferation of these VE/EEs, it is very important to have a robust and reliable Performance Management System (PMS) that enables to control and monitor efficiently and effectively their performance. This is the main objective of the paper. 


\section{BRIEF LITERATURE REVIEW}

Hence, it is possible to identify EE with Supply Chain level and VE with several enterprises (or business units) from different Supply Chains. The authors have conducted a breadth researching throughout the academic literature identifying the most significant existing frameworks for measuring performance at these two domains.

Thus, when measuring supply chain performance, several authors have identified that the usual practice was to extrapolate traditional individual performance measures, such as cost, flexibility or customer response (Beamon, 1999) to the supply chain context, concluding that this practice does not provide a proper PMS for the supply chain. Consequently, they developed several methods that tried to cover this lack. In this sense, Gunasekaran and Tirtiroglu (2001) presented a framework for measuring supply chain performance at the strategic, tactic and operative levels. On the other hand, Chan et al (2003) developed a supply chain model that counted with both tangible and intangible performance measures within multiple dimensions and cross-organisational. This model was improved by Chan and Qi (2003) with the introduction of the called Performance of Activity (POA), which was used to identify both performance measures and metrics, enabling the construction of processes models from the organisations' missions within the supply chain. On the other hand, (Brewer and Speh, 2000) developed a method that modified the traditional Balance Scorecard (BSC) developed by (Kaplan and Norton, 1992) for accomplishing the considerations stated as important ones by supply chain performance measurement experts (Handfield and Nichols, 1999) and (Lee and Billington, 1992). Finally, Burton and Boeder (2003) developed a good approach called Extended Enterprise Assessment Process based on the seven best practices and principle categories, each one having six more specific criteria (42 total criteria), but still not enough to define fully and properly the relationships among the components of the EE.

Only few frameworks deal with measuring performance within a network of enterprises. At this stage, the most relevant work is the one developed by Bullinger, Kühner and Hoof (2002), which presents a hybrid balanced measurement system, integrating both SCOR model (Supply Chain Operations Reference) and adapted balanced scorecards. The metrics of SCOR model focus on controlling both material and product flows by measuring logistic performance. The main motivation of network scorecards is to control logistic networks' business objectives by the measurement of management performance as stated by Gehlen (2002). Together, the metrics constitute a holistic instrument for the measurement of logistic process performance

Within this ambit, Leseure, Shaw and Chapman (2001) introduced the concept of Meta-performance to describe the performance at the network level. Such a concept is a two-dimensional construction, which encloses the concepts of performance and equity within a network. Under this vision, these authors defined a framework for meta-organisational performance measurement in vertical networks. They pointed out that equity should be present at all the levels of networked organisations, measuring both the contribution of each individual member to the VE/EE and the ability of each member to schedule its operations accurately. 
The model developed by Zhao (2002) points in the same direction, determining whether the collaborative activities do transmit an appropriate value to all the involved partners of the network or not.

As a conclusion, it could be stated that there is a clear lack of robust and solid frameworks for both the $\mathrm{VE}$ and the $\mathrm{EE}$, which establish solid relationships through equity and trust practices among the different actors of the VE/EE, by enabling also to keep a clear traceability among the parts.

\section{PMS-EVE FRAMEWORK}

From the above literature review is possible to think that one of the main problems that organisations find when facing the challenge of becoming either a VE or an EE is the lack of both methods and techniques for assessing the necessary efforts in terms of money, human capital, organisation, etc. Therefore, the PMS-EVE model presented in this work provides a definition of methods and techniques that enable evaluation of the organisation's current state as well as the migration model that will drive towards the VE/EE model, assessing at the same time the adequacy of such migration model for managing and achieving the change of state.

"Figure 2" shows the basics of the model, which clearly differentiates between the global or networked level and the local one. In the case of a VE the global level would be the conjoint of several individual enterprises (or business units) from different supply chains and the local one would be composed of every of these individual companies, whereas that in the case of an EE the global level would be the supply chain as a whole and the local one would be constituted by the different actors of the supply chain participating on the EE.

There are two axes, the vertical axis and the horizontal one. On one hand, the former defines the components of the PMS: Goals, objectives, strategies, plans, policies, critical success factors and derived KPIs at both levels global and local. On the other hand, the latter provides four different perspectives to be taken into account when defining the PMS components: Organisation, resources, information and function.

Hence, an objective is the current enunciate of a result that the entity aims to reach in the future, it responds to the question of 'What do we want to measure?'. Then, a strategy is the way of carrying out the entity's activities and processes and of managing the entity's resources to reach the objectives. It responds to the question of 'How do we want to measure the stated objectives?'. On the other hand, the critical success factors CSFs) are those factors that guarantee, through its monitoring and accomplishment, the entity's success. The CSFs are formed by a reduced conjoint of both measurable Objectives and Strategies. Once the Objectives, Strategies and CSFs have been defined, they derive into KPIs that are the final and most operative part of the PMS. 


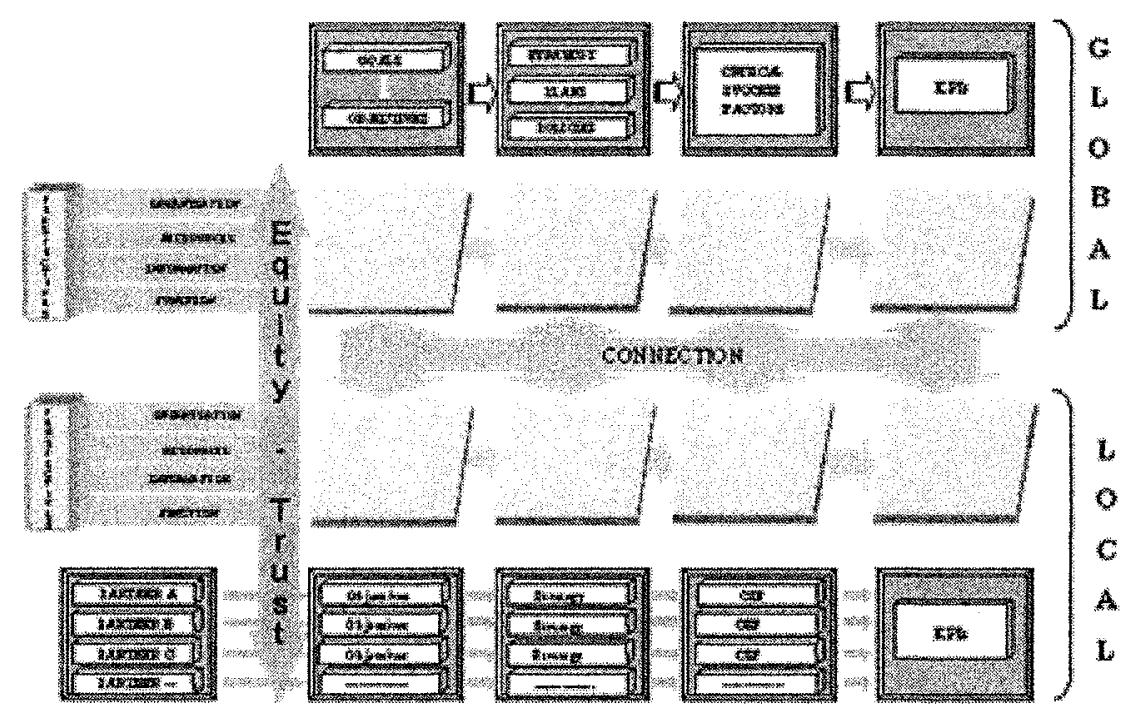

Figure 2: PMS-EVE Integrated proposal

Within a business level, the KPIs evaluate very important states of organisations aiming to join to a VE/EE since they control and assess the current or AS-IS state, the future ideal or TO-BE state, the migration path required for going from the ASIs to the TO-BE state and the quality of the generated results. When carrying out the previous PMS components definition, it is necessary to bear in mind those factors or perspectives considered as of key importance for both the VE/EE and the individual enterprises/business entities forming the network. As "Figure 3" illustrates, we have considered four our model the next four perspectives to be taken into account: Function, Information, Resources and Organisation. These four perspectives are further explained next:

- Function: It is important to set up how the definition of the Objectives, Strategies, CSFs and KPIs will influence to the VE/EE regarding its functionality, and more concretely regarding processes, activities and interrelationships.

- Information: It is necessary to find out what implications the Objectives, Strategies, CSFs and KPIs, from an informational point of view, will have for developing both processes and activities of the VE/EE, and more concretely regarding information needs and structure of the information systems.

- Resources: It is important to identify what needs, regarding resources, will be necessary for accomplishing the Objectives, Strategies, CSFs and KPIs and therefore being able to carry out both processes and activities of the 
$\mathrm{VE} / \mathrm{EE}$, and more concretely regarding economic, human and material (tools) resources.

- Organisation: It is necessary to find out how the definition of Objectives, Strategies, CSFs and KPIs will affect to the VE/EE from an organisational point of view, and more concretely regarding organisational chart, responsibilities and decision-making.

These four perspectives correspond to the modelling skeleton of the Architecture of Open Systems, CIMOSA (Amice, 1989). In this way, our model aims to cover all the aspects that are susceptible of being measured and analysed under these four perspectives. Any element of a VE/EE can be allocated within these four views and therefore it will be a result of the definition of the different performance measurement elements used within the proposal.

As it can be seen in "Figure 3", at the Organisation perspective level, there are defined two objectives, and then three strategies, and then two critical success factors.

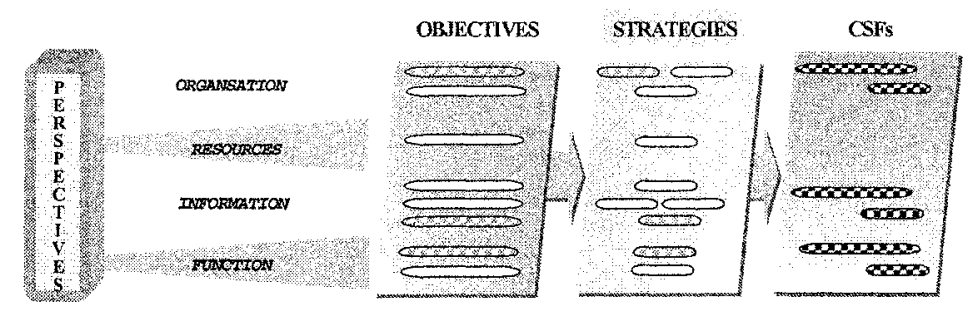

Figure 3: Relationships between Objectives, Strategies and Critical Success Factors and the four relevant perspectives

As stated in the literature review, one of the main objectives for establishing a solid and robust PMS within a VE/EE is to promote and achieve a state of coherence and equity among the partners constituting such VE/EE. In order to achieve such a coherence degree between the different levels, local and global, as well as among the different partners forming the network, the most important thing is to have a PMS that clearly shows the relationships among all the PMS components. Then, it would be possible to unequivocally control and monitor all such PMS components. For doing so, the system must provide a method that clearly shows the traceability from the defined KPIs until the upstream Objectives that these KPIs come from. As shown in "Figure 4", the PMS-EVE model allows such traceability among performance components. Then, it enables and foments coherence between the two main levels, global and local, as the Objectives, Strategies, CSFs and KPIs defined at the Global level are clearly identified with the Objectives, Strategies, CSFs and KPIs defined at the Local one. This approach also enables the easy control and follow-up of equity among the different enterprises forming the network.

Additionally, the PMS-EVE model is a very useful tool for making decisions within VE/EEs since it delivers to decision-makers the whole picture of both the global and the local level, being therefore pretty easy to find relationships and to assess the changes that will take place within the dynamic VE/EE overtime. 


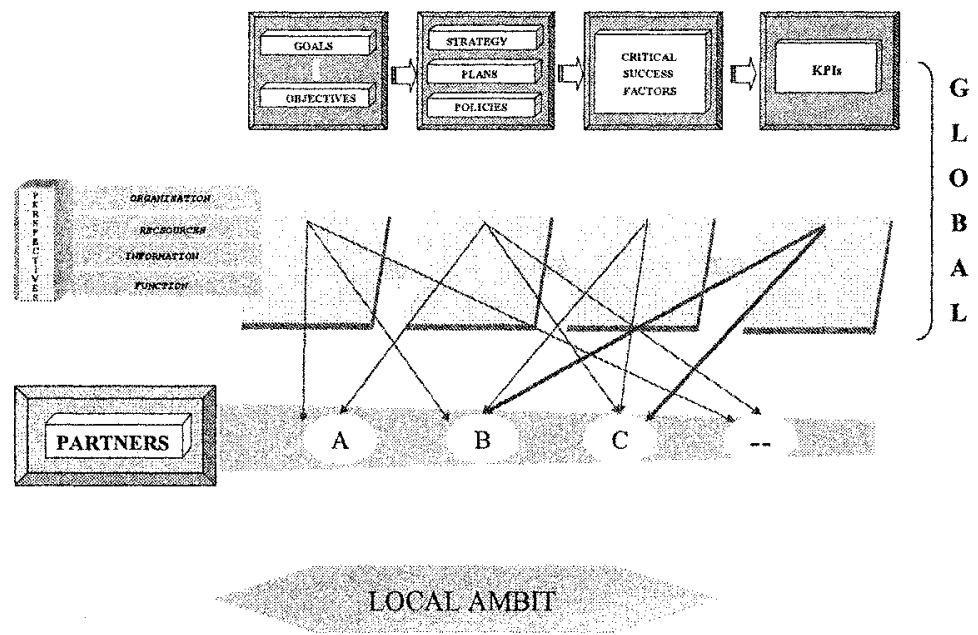

Figure 4: Traceability between the Global and the Local level.

\section{CONCLUSIONS}

This paper has briefly described the frameworks currently available to measure performance at both the EE and the VE. We then identified the gap that such frameworks present and justified the development of our model. Then, we presented the PMS-EVE model, describing its main parts and functionalities and how its application can deliver advantages to organisations that either have joined or are thinking of joining an EE/VE.

\section{REFERENCES}

AMICE (1989), Consortium 'Open System Architecture for CIM, Research Reports ESPRIT/Project 688 AMICE' Springer-Verlag 1989.

Beamon, Benita M. (1999): "Measuring supply chain performance", International Journal of Operations and Production Management, Vol. 19, N 3, pp. 275-292.

Brewer, P.C. and Speh, T.W. (2000), "Using the Balanced Scorecard to measure supply chain performance", Journal of Business Logistics, Vol. 21, No. 1, pp. 75-94.

Browne, J.; Sackett, P.; Wortmann, H: (1994), Industry requirements and associated research issues in the extended enterprise, Proceedings of the European Workshop on Integrated Mamufacturing Systems Engineering, IMSE'94, Grenoble, December 12-14, pp. 9-16.

Bullinger, H.J.; Kühner, M.; Hoof, A.V. (2002): “Analysing supply chain performance using a balanced measurement method", International Journal of Production Research; Vol, 40, No 15, pp. 3533-3543. 
Burton, T.T. and Boeder, S.M (2003): The Lean Extended Enterprise: Moving Beyond the Four Walls to Value Stream Excellence. J. Ross Publishing, Inc. Florida.

Caskey, K.R. (1995): Co-operative distributed simulation and optimization in extended enterprises, Proceedings of the IFIP WG5.7 Working Conference on Managing Concurrent Manufacturing to Improve Industrial Performance, Seattle, pp. 23-32.

Chan, T.S.; Qi, H.J. (2003): "Feasibility of performance measurement system for supply chain: a processbased approach and measures", Integrated Manufacturing Systems; Vol. 14, N 3, pp. 179-190.

Chan, T.S.; Qi, H.J.; Chan, Henry C.W.; Ip, Ralph W.L. (2003): “A conceptual model of performance environment"; International Journal of Operations \& Production Management; Vol. 21, No 1/2, pp. 71-87.

Dyer, J. H. (2000): Collaborative Advantage: Winning Through Extended Enterprise Supplier Networks. Oxford University Press. New York.

Gehlen de Leao, A. (2002), "A business logistics approach to design performance evaluation systems", Papers from the Third International Conference on Performance Measurement and Management (PMA 2002), July.

Gunasekaran, A.; Patel, C.; Tirtiroglu, E. (2001): "Performance measures and metrics in a supply chain" measurement for supply chains, Management Decision; Vol. 41, $\mathrm{N}^{\circ}$ 7, pp. 635-642.

Handfield, R.B., and Nichols, E.L. (1999), Introduction to supply chain management, Prentice may Upper Saddle River, NJ.

Jagou, P. Concurrent engineering, French version, Hermès, Paris (1993).

Kaplan, R.S.; Noron, D. P. (1992): "The balanced scorecard. Measures that drive performance", Harvard Bisiness review. Jan/Feb, pp. 71-79.

Lee, H.l. and Billington, C. (1992): "Managing supply chain inventory: Pitfalls and opportunities", Sloan Management Review, Vol. 33, Spring, No. 3, pp. 65-73.

Leseure M.; Shaw N.; Chapman G. (2001): "Performance measurement in organisational networks: an exploratory case study"; International Journal of Business Performance Management; Vol. 3, $\mathrm{N}^{\mathrm{o}} 1$, pp. $30-46$.

.Moller, C.; Riis, J. O.; Hansen, M. (1997): Department of Production, Aalborg University, "A framework for studing industrial networks".

Preiss, K.;_Steven, L.; Roger, N.N. (1996): "Cooperate to Compete Building Agile Business Relationships", Van Nostrand Reinhold,.

.Riis, J.O. (1997): IFIP WG 5.7 Ascona Working Conference, Switzerland.

Zhao, F. (2002), "Measuring inter-organizational partnerships: The challenge of cultural discrepancy"; Papers from the Third International Conference on Performance Measurement and Management (PMA 2002), July. 